\title{
Positive Response of Hyoscyamus pusillus Callus Cultures to Exogenous Melatonin on Biochemical Traits and Secondary Metabolites under Drought Conditions
}

\author{
Shamil I. Neamah $\mathbb{D}^{1}$ and Nisreen A. Jdayea ${ }^{2}$ \\ ${ }^{1}$ Plant Tissue Culture Division, Department of Combat Desertification, Center of Desert Studies, University of Anbar, \\ Ramadi, Iraq \\ ${ }^{2}$ The General Directorate of Education in Anbar, Ramadi, Iraq \\ Correspondence should be addressed to Shamil I. Neamah; ds.dr.shamil@uoanbar.edu.iq
}

Received 28 August 2021; Revised 10 January 2022; Accepted 13 January 2022; Published 3 February 2022

Academic Editor: Maria Serrano

Copyright $\odot 2022$ Shamil I. Neamah and Nisreen A. Jdayea. This is an open access article distributed under the Creative Commons Attribution License, which permits unrestricted use, distribution, and reproduction in any medium, provided the original work is properly cited.

\begin{abstract}
There is increased attention from specialists toward producing natural compounds from plant tissues through the combined use of elicitors. The present study investigated the effects of melatonin treatment in normal and drought stress conditions for sustainable production of biomass and secondary antioxidant metabolites in a Hyoscyamus pusillus four-month-old callus cultures. For this purpose, we used multiple concentrations of melatonin $\left(0,0.5,1.0,1.5\right.$, and $\left.2.0 \mathrm{mg} \mathrm{l}^{-1}\right)$ to assess its ability to improve growth, physiological, and biochemical properties of $H$. pusillus. There was two drought stress levels $\left(0\right.$ and $\left.30 \mathrm{gl}^{-1}\right)$ of polyethylene glycol (PEG). It was harvested in 28 days. The results showed a significant decrease with an increase in the concentration of PEG treatment in growth and physiological traits compared to the results of those samples when treated with melatonin. Results showed an increase in oxidative stress in tissue treated with PEG due to a significant increase in the content of hydrogen peroxide $\left(\mathrm{H}_{2} \mathrm{O}_{2}\right)$ and malondialdehyde (MDA). The decreased oxidative stress was associated with an increased antioxidant enzyme activity superoxide dismutase (SOD), and catalase (CAT) in the samples was treated by melatonin, which resulted in increased membrane stability index (MSI) and enhanced growth traits under the PEG treatment compared to the control. By reducing the activity of phenylalanine ammonia-lyase (PAL) and peroxidase (POX), moisture tightening increased the production of phenolic compounds (PC) and flavonoid compounds (FC) in callus cultures, and high concentrations of melatonin were combined with them to improve their production. Therefore, it can be asserted that a moderate treatment with melatonin is more suitable under water stress conditions to produce secondary compounds from $H$. pusillus.
\end{abstract}

\section{Introduction}

Plants are essential to sustain human life. In addition to being used as food, they are used as the main source of pharmaceutical industries for most of the world's population. Wild plants are characterized by their content of phytochemicals known as secondary metabolites that are used in various industries [1]. The genus Hyoscyamus is an important plant genus that has a wide range of plant species, including the pusillus, a plant species with medicinal properties that belongs to the Solanaceae family [2]. The plant is classified among the endangered plants in the western desert of Iraq due to overgrazing and lack of rain, which leads to the loss of an important plant that can provide essential natural compounds for the pharmaceutical industry. The plant's rich content is characterized by inactive compounds such as alkaloids [3], phenolic acids, flavonoids, terpenoids, tannins, and steroids [4], from which a wide range of bioactivities can be derived such as antioxidant, antifungal, antibacterial, antibacterial [4], antispasmodic, anticholinergic, mydriatic, sedative, and analgesic derivatives [5]. Biotechnology, particularly plant tissue culture techniques, plays a distinct role in stimulating the metabolic pathways responsible for producing secondary metabolites. 
It provides the necessary solutions to many of the problems facing the production of these compounds from their natural sources, such as the geographical distribution of the plant, the unfavorable environmental conditions, high economic cost, low productivity, difficult purification, the shortage of agricultural lands to grow medicinal plants due to the competition with other economic crops, and the lack of suitable land for cultivation [6-8].

Polyethylene glycol is a long-chain polymer compound, water-soluble and nonionic [9]. It has osmotic properties to enhance drought stress in the medium by increasing osmosis and growth of plant cells under the stress of aqueous deficit like dehydration under normal conditions without toxic effects $[10,11]$. Several studies have confirmed that the induction of drought stress is one method used to increase the secondary compounds in calli cultures. While it negatively affects the accumulation of biomass, it can contribute to the production of secondary metabolites in calli cultures [12-15].

Melatonin (N-acetyl-5-methoxytryptamine) is a nontoxic chemical compound produced by various plant organs. It was classified as a newly discovered plant growth regulators $[16,17]$. Several studies have reported the prominent role of melatonin in plant growth and development. It provides the necessary protection for the plant cell from the negative impact of various abiotic stresses [18-22] by stimulating gene expression [23] leading to the activation of the antioxidant enzymatic and nonenzymatic systems [24-29]. Melatonin is believed to have key role in increasing the mitochondrial efficiency of the electron transport chain. Thus, melatonin plays an important role in the stability of biofilms [30] and protecting them from the impact of oxidative damage [30-33]. Determining the efficacy of exogenous melatonin under water stress conditions is essential to study its ability to elicit defensive responses in calli cultures and their effects on the production secondary metabolites.

To our knowledge, till date, there is no research article available explaining the effects of the interaction between melatonin treatment and osmotic stress on the biomass accumulation of callus and the responses of plant defense systems as well as their implications for the production of plant antioxidants. Therefore, the present article aims to evaluate $H$. pusillus tissue cultures' response to exogenous addition of melatonin under normal and aqueous tension conditions using PEG in enhancing biomass and biochemical characteristics and reflecting these changes in the production of desired levels of phenolic metabolites and flavonoids in a $H$. pusillus calli cultures.

\section{Materials and Methods}

2.1. Seed Germination. H. pusillus seeds were provided from the desert environment museum (University of Anbar, Iraq). The seeds were surface sterilized by placing them in an Erlenmeyer flask with detergent liquid added and washed well under tap water for 30 minutes. They were inserted into a laminar flow and sterilized using 3\% sodium hypochlorite solution for 15 minutes. They were then rinsed with sterile distilled water five times. The sterilized seeds were cultured in a preprepared MS medium with $30.0 \mathrm{~g} \mathrm{l}^{-1}$ sucrose and $7.0 \mathrm{~g} \mathrm{l}^{-1}$ agar, incubated at $25^{\circ} \mathrm{C}$ and a light/dark period of $8 /$ 16 hours to obtain the sterile seedlings.

2.2. Callus Induction. H. pusillus was callus induced by cultures of cotyledons from sterilized seedlings in MS medium supplemented with $3.0 \mathrm{mg}^{-1}$ 2,4-D, $0.5 \mathrm{mg} \mathrm{l}^{-1} \mathrm{Kin}$., $0.5 \mathrm{mg} \mathrm{l}^{-1} \mathrm{GA}, 0.25 \mathrm{mg} \mathrm{l}^{-1} \mathrm{NAA}$ and $30.0 \mathrm{~g} \mathrm{l}^{-1}$ sucrose. The $\mathrm{pH}$ was adjusted to 5.7, after which the $7.0 \mathrm{~g}^{-1}$ agar was added. The explants were incubated at $25^{\circ} \mathrm{C}$ for 28 days in the darkness.

2.3. Establishment and Treatment of Callus Cultures. H. pusillus callus cultures were initiated from several subcultures on the MS medium ( $\mathrm{pH}$ 5.8) supplemented with $2.0 \mathrm{mg} \mathrm{l}^{-1}$ 2,4-D, $0.5 \mathrm{mg} / \mathrm{l} \mathrm{kin.,} 30 \mathrm{~g} \mathrm{l}^{-1}$ sucrose, and $7.0 \mathrm{~g} \mathrm{l}^{-1}$ agar as a callus cultures reproduction media, and the cultures were incubated at $25 \pm 2{ }^{\circ} \mathrm{C}$ in darkness. The formed callus cultures were treated with study agents that included polyethylene glycol at concentration $(0$ and 30$) \mathrm{g} \mathrm{l}^{-1}$ and melatonin at concentrations $0,0.5,1.0,1.5$, and $2.0 \mathrm{mg} \mathrm{l}^{-1}$. The callus was harvested after 28 days for the specified measurements.

2.3.1. Callus Morphology and Growth Traits. Callus color was determined by visual inspection. The fresh weight of the callus was determined by separating the callus samples from the culture media and removing the remaining media attached to it. The dry weight of the callus was determined based on oven-dried callus weight at $40^{\circ} \mathrm{C}$ for $48 \mathrm{~h}$.

2.3.2. Callus Physiological Traits. The total chlorophyll content was determined based on the method described by Lichtenthaler and Buschmann [34]. Briefly, $0.25 \mathrm{~g}$ was taken from a homogeneous sample of soft callus crushed by liquid nitrogen. Then, $10 \mathrm{ml}$ of acetone was added and centrifuged at $5000 \mathrm{rpm}$ for $5 \mathrm{~min}$. The absorbance of the supernatant was determined at wavelengths 660 and $642.5 \mathrm{~nm}$. The membrane stability index was determined in a sample of $200 \mathrm{mg}$ fresh weight of callus according to the addition of $10 \mathrm{ml}$ of distilled water. It was divided into two groups. The first group was placed in a water bath at $40^{\circ} \mathrm{C}$ for 30 minutes. Then, the electrical conductivity was recorded after being cooled to $25^{\circ} \mathrm{C}$. In the same way, the second group was heated to $100^{\circ} \mathrm{C}$ for 15 minutes. Then, the electrical conductivity was measured, followed by measuring the membrane stability index [35]. The relative water content of callus cultures was calculated by soaking fresh callus in water distilled and then weighed to obtain the turgid weight (TW). Then, the calculation was done based on the previously described formula by Karimi et al. [36].

2.3.3. Content $\mathrm{H}_{2} \mathrm{O}_{2}$. The spectrophotometric method according to Velikova et al. [37] was used to determine the content of $\mathrm{H}_{2} \mathrm{O}_{2}$ from callus samples. Briefly, $250 \mathrm{mg}$ of fresh callus was added in $2.5 \mathrm{ml}$ of $0.1 \%$ tri-chloroacetic acid 
(TCA) and centrifuged at $12,000 \mathrm{rpm}$ for $15 \mathrm{~min}$. Then, $500 \mu \mathrm{l}$ of the supernatant solution was added to $500 \mu \mathrm{l}$ of $10 \mathrm{mM}$ K-phosphate buffer ( $\mathrm{pH}$ 7.0) and $1000 \mu \mathrm{l}$ of KI $(1.0 \mathrm{M})$. The absorbance of the supernatant was determined at $390 \mathrm{~nm}$. The concentration of $\mathrm{H}_{2} \mathrm{O}_{2}$ was determined using a $\mathrm{H}_{2} \mathrm{O}_{2}$ standard curve.

2.3.4. Lipid Peroxidation Assay. The amount of malondialdehyde (MDA) production in the assay was measured based on the report provided by De Vos et al. [38]. In short, $300 \mathrm{mg}$ of fresh callus was homogenized in $10 \mathrm{ml}$ of $0.25 \%$ TBA dissolved in $10 \%$ TCA. The extract was heated at $95^{\circ} \mathrm{C}$ for 30 minutes and then immediately cooled on ice. After that, we used the centrifugation at 3,000 rpm for $10 \mathrm{~min}$. The concentration of MDA was measured by deducting the absorbance at 600 and $532 \mathrm{~nm}$ using an extinction coefficient of $155 \mathrm{mM}^{-1} \mathrm{~cm}^{-1}$.

2.3.5. Determination of Enzyme Activity. Antioxidant enzymes analysis was carried out according to the provided method of Gapinska et al. [39]. The enzyme was extracted from $500 \mathrm{mg}$ of fresh callus which was symmetrized in potassium phosphate buffer $(50 \mathrm{mM}, \mathrm{pH}$ 7) including $1 \mathrm{mM}$ EDTA and $1 \%$ polyvinylpyrrolidone (PVP). Then, the centrifugation of $10,000 \mathrm{rpm}$ at $4^{\circ} \mathrm{C}$ for $15 \mathrm{~min}$ was applied to measure the enzymatic activity.

The SOD activity level was described by Beauchamp and Fridovich [40]. The assay mixture consisted of $100 \mu \mathrm{l}$ of the enzyme extract, $50 \mathrm{mM} \mathrm{K}$-phosphate buffer $(\mathrm{pH}$ 7.8), $2 \mu \mathrm{M}$ riboflavin, $13 \mathrm{mM}$ methionine, $0.1 \mathrm{mM}$ EDTA, and $75 \mu \mathrm{l}$ nitroblue-tetrazolium (NBT). The reactions mixture was carried out at $25^{\circ} \mathrm{C}$ under a light bank consisting of eight fluorescent lamps with intensity of around $15 \mathrm{~W}$ for $10 \mathrm{~min}$. After the completion of the reaction, the activity of SOD enzyme was determined at an absorbance level of $560 \mathrm{~nm}$, based on a level of photoreduction by $50 \%$ of NBT.

The CAT activity was measured based on the decrease in $\mathrm{H}_{2} \mathrm{O}_{2}$ absorption at $240 \mathrm{~nm}$ for $30 \mathrm{~s}$ using $3.8 \mathrm{mM}^{-1} \mathrm{~cm}^{-1}$ as an extinction coefficient [41]. The reaction mixture consisted of $15 \mathrm{mM}$ of $\mathrm{H}_{2} \mathrm{O}_{2}$, and $50 \mathrm{mM} \mathrm{K}$-phosphate buffer at $\mathrm{pH} 7.0$ and $25^{\circ} \mathrm{C}$ with $50 \mu \mathrm{l}$ of enzyme extract.

PAL activity was determined as described by Lin and $\mathrm{Wu}$ [42]. Briefly, $100 \mu \mathrm{l}$ of the enzymatic extract was added to $1000 \mu \mathrm{l}$ of borate buffer at $\mathrm{pH}$ 8.8. The callus cultures were ground with a pestle and mortar on a makeshift pretzel $\left(0.15 \mathrm{~g} \mathrm{ml}^{-1}\right)$ for 2 minutes on ice. Then, centrifugation of $1000 \mathrm{rpm}$ for $20 \mathrm{~min}$ under $4^{\circ} \mathrm{C}$ was carried out. The PAL activity was determined based on its transformation to cinnamic acid.

POX activity was estimated based on the report of Abeles and Biles [43]. In short, the components of the reaction mixture included $2 \mathrm{ml}$ of acetate buffer $(0.2 \mathrm{M}, \mathrm{pH} 4.8)$, and $200 \mu \mathrm{l}$ of benzidine $(40 \mathrm{mM}) .200 \mu \mathrm{l}$ of $\mathrm{H}_{2} \mathrm{O}_{2}$ was added to the reaction, and purified anionic POX was added at $20 \mu \mathrm{l}$. The absorbance was measured at $530 \mathrm{~nm}$.
2.3.6. Nonenzymatic Antioxidants. The phenolic content in callus tissue was determined based on modified protocol of Velikova et al. [37]. Briefly, $100 \mathrm{mg}$ of dried callus was added in $20 \mathrm{ml}$ of the methanol $80 \%$ and sonicated at $25^{\circ} \mathrm{C}$ for $20 \mathrm{~min}$. Then, we centrifuged for $20 \mathrm{~min}$ at $15,000 \mathrm{rpm}$. The supernatant was dried by a vacuum evaporator, resolved in $1 \mathrm{ml}$ methanol, and used for the determination of phenolic compounds. The absorbance of the mixed solution was measured at $725 \mathrm{~nm}$ using gallic acid in the standard curve [44]. Total flavonoids were estimated as catechin equivalents. The absorbance was measured at $510 \mathrm{~nm}$. The results were expressed as mg catechin $\mathrm{g}^{-1} \mathrm{DW}$ [45].

2.4. Experimental Design and Statistical Analysis. The coefficients were distributed using the complete randomized design system (CRD). The data of three replicates were subjected to one-way analysis of variance (ANOVA), and Duncan's multiple range test (DMRT) was used to determine the significant differences for the several samples at $P \leq 0.05$ by the statistical software package (GenState $24^{\text {th }}$ Edition).

\section{Results and Discussion}

3.1. Morphological Changes and Biomass Accumulation. The effect of PEG and melatonin on morphological changes and biomass fresh weight (FW) and dry weight (DW) of calli cultures was tested in a $H$. pusillus calli cultures.

Greenish white color was obtained for calli cultures nontreated with PEG and melatonin. A color change from greenish white to greenish brown was observed with an increased concentration of melatonin, whereas the melatonin-free PEG 4\% treated callus cultures acquired a dark brown color. This color changed to light brown with increasing melatonin concentration (Table 1 and Figure 1). The main reason for the dark brown coloration of calli tissue is the accumulation of phenolic compounds due to drought stress [12, 13,46], whereas melatonin treatment contributed to relieving stress by changing the dark color to light brown or brownish white. This may be due to its ability to protect the cell from the negative effects of abiotic stress [47].

The highest mean values significantly increased in FW, and DW (7.115 and $0.515 \mathrm{~g}$ ) was observed in 4\% PEG with treating calli cultures at a concentration of 1.0 or $1.5 \mathrm{mg}$ $1^{-1}$, respectively, under drought-free conditions. The biomass of the callus culture in the combination $(4 \%$ PEG +0 melatonin) was significantly decreased by 2.522 and $0.180 \mathrm{~g}$ in FW and DW, respectively. Conversely, melatonin-enhanced biomass accumulation under drought stress by increasing the FW and DW (Table 1). Our observations were supported by investigations revealing the role of melatonin processing in biomass enhancement [27]. It was observed that the inclusion of PEG in the culture medium reduced the growth of tissue cells, thus causing their deterioration [12, 48, 49]. Melatonin can enhance plant tolerance to abiotic stress and stimulate cell growth $[50,51]$. This may be due to the positive role 
TABLE 1: The morphological traits, fresh weight (FW), and dry weight (DW) in $H$. pusillus calli cultures treated with melatonin concentrations and PEG levels after 28 days.

\begin{tabular}{|c|c|c|c|}
\hline Treatments & Callus color & FW (g) & DW (g) \\
\hline PEG $0 \%+$ melatonin $0 \mathrm{mg} \mathrm{l}^{-1}$ & Greenish white & $5.457 \pm 0.121^{\mathrm{e}}$ & $0.377 \pm 0.025^{\mathrm{d}}$ \\
\hline PEG $0 \%+$ melatonin $0.5 \mathrm{mg} \mathrm{l}^{-1}$ & Green & $6.051 \pm 0.080^{f}$ & $0.431 \pm 0.006^{\mathrm{e}}$ \\
\hline PEG $0 \%+$ melatonin $1.0 \mathrm{mg} \mathrm{l}^{-1}$ & Green & $7.115 \pm 0.343^{\mathrm{i}}$ & $0.502 \pm 0.012^{\mathrm{fi}}$ \\
\hline PEG $0 \%+$ melatonin $1.5 \mathrm{mg} \mathrm{l}^{-1}$ & Greenish brown & $6.698 \pm 0.218^{g}$ & $0.515 \pm 0.007^{\mathrm{i}}$ \\
\hline PEG $0 \%+$ melatonin $2.0 \mathrm{mg} \mathrm{l}^{-1}$ & Brown & $6.707 \pm 0.275^{\mathrm{gh}}$ & $0.492 \pm 0.009^{f}$ \\
\hline PEG $4 \%+$ melatonin $0 \mathrm{mg} \mathrm{l}^{-1}$ & Dark brown & $2.522 \pm 0.181^{\mathrm{a}}$ & $0.180 \pm 0.013^{\mathrm{a}}$ \\
\hline PEG $4 \%+$ melatonin $0.5 \mathrm{mg} \mathrm{l}^{-1}$ & Reddish brown & $3.575 \pm 0.189^{\mathrm{ab}}$ & $0.259 \pm 0.017^{\mathrm{b}}$ \\
\hline PEG $4 \%+$ melatonin $1.0 \mathrm{mg} \mathrm{l}^{-1}$ & Brown & $3.758 \pm 0.116^{\mathrm{b}}$ & $0.266 \pm 0.006^{\mathrm{b}}$ \\
\hline PEG $4 \%+$ melatonin $1.5 \mathrm{mg} \mathrm{l}^{-1}$ & Light brown & $4.044 \pm 0.140^{c}$ & $0.309 \pm 0.010^{\mathrm{c}}$ \\
\hline PEG 4\% + melatonin $2.0 \mathrm{mg} \mathrm{l}^{-1}$ & Brownish white & $4.460 \pm 0.306^{\mathrm{d}}$ & $0.312 \pm 0.023^{\mathrm{c}}$ \\
\hline
\end{tabular}

Data show the mean values \pm standard errors of triplicates. Different alphabets indicate significant statistical differences between the mean values based on Duncan's test at $P \leq \% 5$.

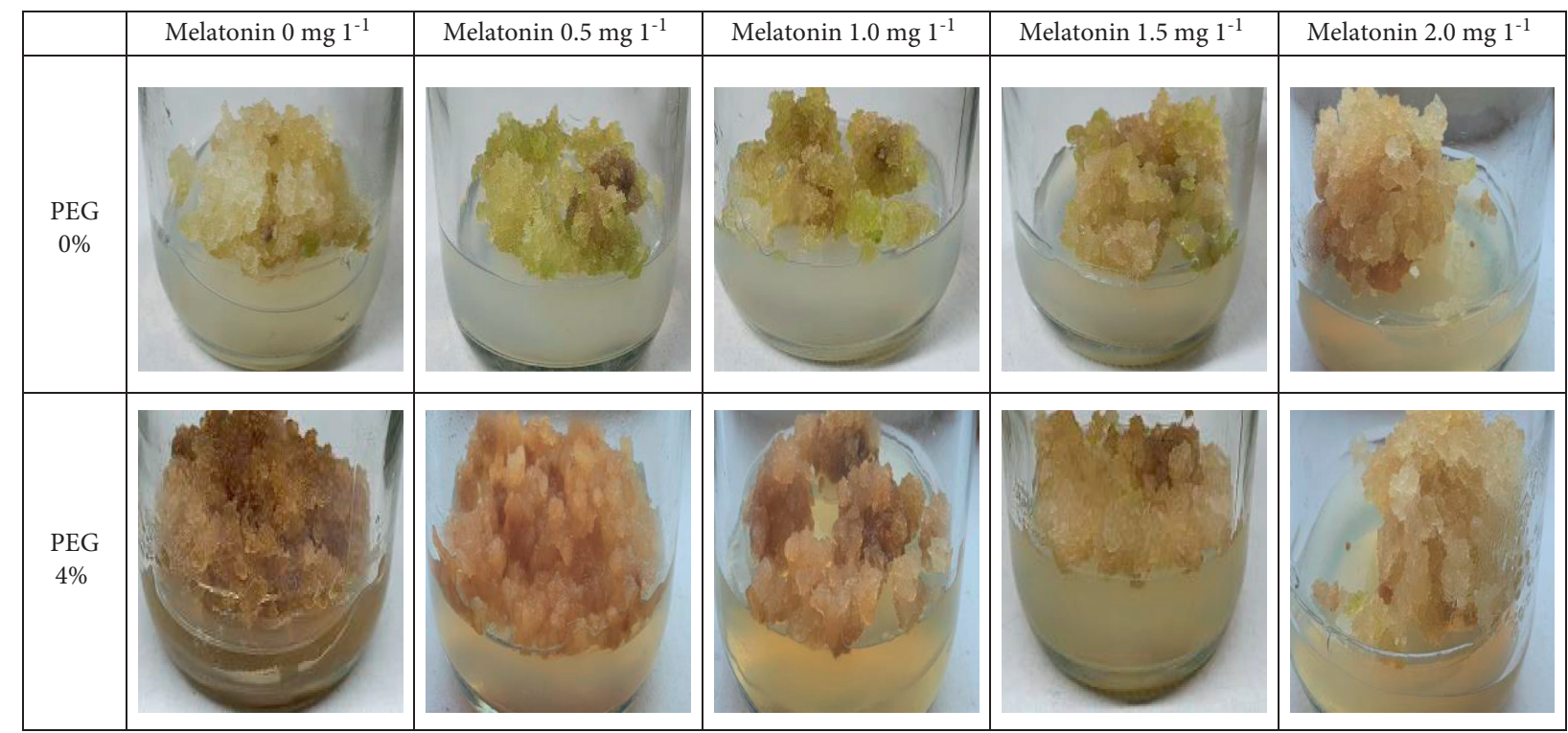

FIgURE 1: Morphological changes and biomass traits in melatonin treated H. pusillus callus cultures on medium with or without PEG.

that melatonin plays in inducing the biosynthesis of indole-acetic acid in plant cells [52], contributing to the promotion of biomass accumulation [27].

\subsection{Physiological Traits. Physiological changes in melatonin} treated $H$. pusillus calli cultures in media free or containing of drought stress by PEG are shown in Table 2 .

The total chlorophyll content was significantly increased in callus cultures grown in PEG-free media. The melatonin concentration was reached at $2.85 \mathrm{mg} \mathrm{g}^{-1} \mathrm{FW}$ in $1.0 \mathrm{mg} \mathrm{l}^{-1}$, compared to the control treatment, which was $2.47 \mathrm{mg} \mathrm{g}^{-1}$ FW. Furthermore, melatonin treatment caused an improvement in the total chlorophyll content of the developing callus under drought conditions, the concentration of $2.0 \mathrm{mg}$ $\mathrm{I}^{-1}$, a significant increase of $2.15 \mathrm{mg} \mathrm{g}^{-1} \mathrm{FW}$ compared to the control treatment, which showed the lowest total chlorophyll content at $0.99 \mathrm{mg} \mathrm{g}^{-1} \mathrm{FW}$.

The membrane stability index was observed to increase with increasing melatonin concentration significantly. The concentration of melatonin at $2.0 \mathrm{mg} \mathrm{l}^{-1}$ showed the highest mean values of 86.48 compared with the concentration of $0.5 \mathrm{mg} \mathrm{l}^{-1}$ by 73.61. However, the results showed the same concentration of melatonin treated in media containing drought condition by 66.77, compared to the control treatment, which showed the lowest mean values for this trait (45.48).

The RWC significantly increased in callus cultures grown in media free from drought conditions and treated with a high melatonin concentration by $6.12 \%$, compared to $0.5 \mathrm{mg}^{-1}$ of melatonin concentrations. Melatonin treatment caused an increase in the RWC of the enhancing callus under drought conditions. The concentration of $2.0 \mathrm{mg}^{-1}$ achieved a significant increase of $66.77 \%$ compared to the control, which showed the lowest percentage of $57.41 \%$.

The callus cultures grown under abiotic stress conditions are negatively affected in Chl.T, MSI, and RWC, leading to increased oxidative stress. This caused damage to some cellular components [27, 53-55]. 
TABLE 2: Total chlorophyll (Chl T), membrane stability index (MSI), and relative water content (RWC) in $H$. pusillus calli cultures treated with melatonin and PEG levels after 28 days.

\begin{tabular}{|c|c|c|c|}
\hline Treatments & Chl T (mg g-1 FW) & MSI & RWC (\%) \\
\hline PEG $0 \%+$ melatonin $0 \mathrm{mg} \mathrm{l}^{-1}$ & $2.47 \pm 0.121^{\mathrm{ef}}$ & $75.49 \pm 2.030^{\mathrm{fg}}$ & $82.88 \pm 0.697^{f}$ \\
\hline PEG $0 \%+$ melatonin $0.5 \mathrm{mg} \mathrm{l}^{-1}$ & $2.62 \pm 0.025^{\mathrm{gh}}$ & $73.61 \pm 1.581^{\mathrm{f}}$ & $82.06 \pm 1.320^{f}$ \\
\hline PEG $0 \%+$ melatonin $1.0 \mathrm{mg} \mathrm{l}^{-1}$ & $2.85 \pm 0.076^{\mathrm{i}}$ & $80.23 \pm 2.096^{\mathrm{h}}$ & $83.93 \pm 2.165^{f}$ \\
\hline PEG $0 \%+$ melatonin $1.5 \mathrm{mg} \mathrm{l}^{-1}$ & $2.72 \pm 0.123^{h}$ & $85.21 \pm 1.616^{\mathrm{i}}$ & $87.03 \pm 1.243^{\circ}$ \\
\hline PEG $0 \%+$ melatonin $2.0 \mathrm{mg} \mathrm{l}^{-1}$ & $2.52 \pm 0.090^{\mathrm{fg}}$ & $86.48 \pm 2.761^{\mathrm{i}}$ & $87.08 \pm 0.656^{\mathrm{g}}$ \\
\hline PEG $4 \%+$ melatonin $0 \mathrm{mg} \mathrm{l}^{-1}$ & $0.99 \pm 0.084^{\mathrm{a}}$ & $45.48 \pm 2.336^{\mathrm{a}}$ & $57.41 \pm 1.234^{\mathrm{a}}$ \\
\hline PEG $4 \%+$ melatonin $0.5 \mathrm{mg} \mathrm{l}^{-1}$ & $1.43 \pm 0.139^{\mathrm{b}}$ & $54.19 \pm 2.237^{\mathrm{b}}$ & $66.14 \pm 1.279^{\mathrm{b}}$ \\
\hline PEG $4 \%+$ melatonin $1.0 \mathrm{mg} \mathrm{l}^{-1}$ & $1.95 \pm 0.100^{c}$ & $57.22 \pm 1.257^{\mathrm{c}}$ & $67.73 \pm 2.041^{\mathrm{C}}$ \\
\hline PEG $4 \%+$ melatonin $1.5 \mathrm{mg} \mathrm{l}^{-1}$ & $2.14 \pm 0.031^{\mathrm{d}}$ & $63.11 \pm 1.926^{\mathrm{d}}$ & $72.07 \pm 1.206^{\mathrm{C}}$ \\
\hline PEG $4 \%+$ melatonin $2.0 \mathrm{mg} \mathrm{l}^{-1}$ & $2.15 \pm 0.174^{\mathrm{d}}$ & $66.77 \pm 1.424^{\mathrm{e}}$ & $75.28 \pm 1.252^{\mathrm{e}}$ \\
\hline
\end{tabular}

Data show the mean values \pm standard errors of triplicates. Different alphabets indicate significant statistical differences between the mean values based on Duncan's test at $P \leq \% 5$.
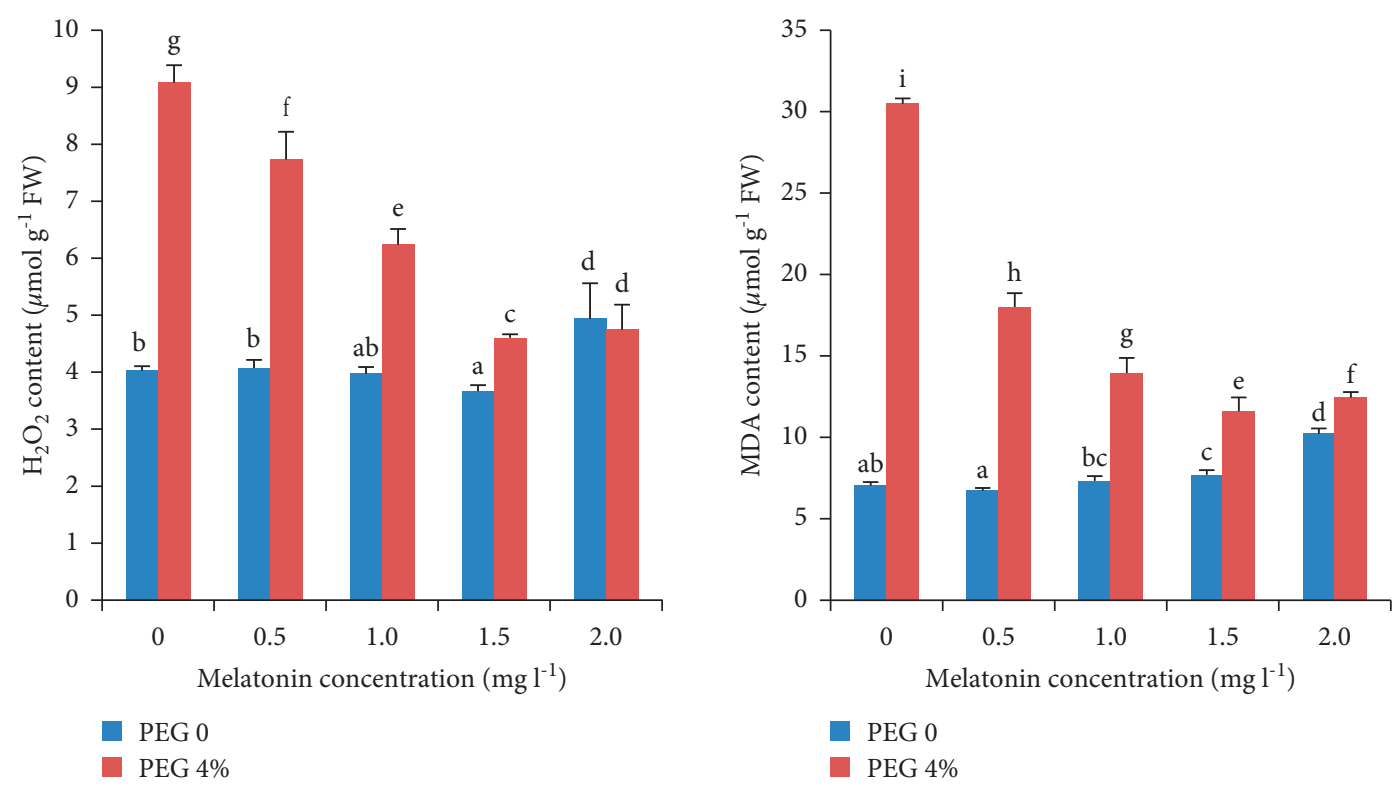

Figure 2: $\mathrm{H}_{2} \mathrm{O}_{2}$ and MDA content in $\mathrm{H}$. pusillus calli cultures treated with melatonin concentrations and PEG levels after 28 days. Vertical bars indicate the standard errors of triplicates. Different alphabets indicate significant statistical differences between the mean values based on Duncan's test at $P \leq \% 5$.

Melatonin treatment improved the harmful effects of dehydration stress on all measured physiological characteristics. Our data are consistent with previous literature indicating a role for melatonin in the improvement of total chlorophyll content in Lupinus termis L. and Solanum lycopersicum L. under water stress conditions [28, 56]. Melatonin treatment contributes to protecting chlorophyll pigments from degradation by the harmful effects of drought by stimulating gene expression responsible for regulating some genes such as Chl$\mathrm{PRX}$, Chlase and PPH. that protect the degradation of plant cell pigments [57]. It stimulates the cell's defence system against the adverse effects of ROS, which leads to the maintenance of the various cellular components [58].

3.3. $\mathrm{H}_{2} \mathrm{O}_{2}$ and $\mathrm{MDA}$ Content. $\mathrm{H}_{2} \mathrm{O}_{2}$ and MDA assays showed significant differences in melatonin-treated callus cultures in PEG-free or PEG-containing media as shown in Figure 2.
$\mathrm{H}_{2} \mathrm{O}_{2}$ content was reduced by higher melatonin concentrations. This role is apparent in media containing PEG as melatonin concentration of $1.5 \mathrm{mg} \mathrm{l}^{-1}$ showed decreased by $97.23 \%$ compared to the comparison treatment. In comparison, most of the melatonin concentrations were not significantly affected for the mean values of PEG-free media.

The MDA content increased at PEG levels, and was enhanced further by the melatonin treatment.

Melatonin contributed to a significant increase in PEG-free media with a concentration of $2.0 \mathrm{mg} \mathrm{l}^{-1}$ that reached $4.94 \mu \mathrm{mol} \mathrm{g}{ }^{-1} \mathrm{FW}$. Conversely, a significant decrease was obtained by treating media containing PEG with melatonin, with a decrease of 2.25-fold compared to the control treatment.

In our study, PEG treatment induced an increase in oxidative stress by increasing the level of free radicals, resulting in damage to cell membranes. The negative impact of drought stress on $\mathrm{H}_{2} \mathrm{O}_{2}$ and MDA accumulation has been reported [36, 49]. 

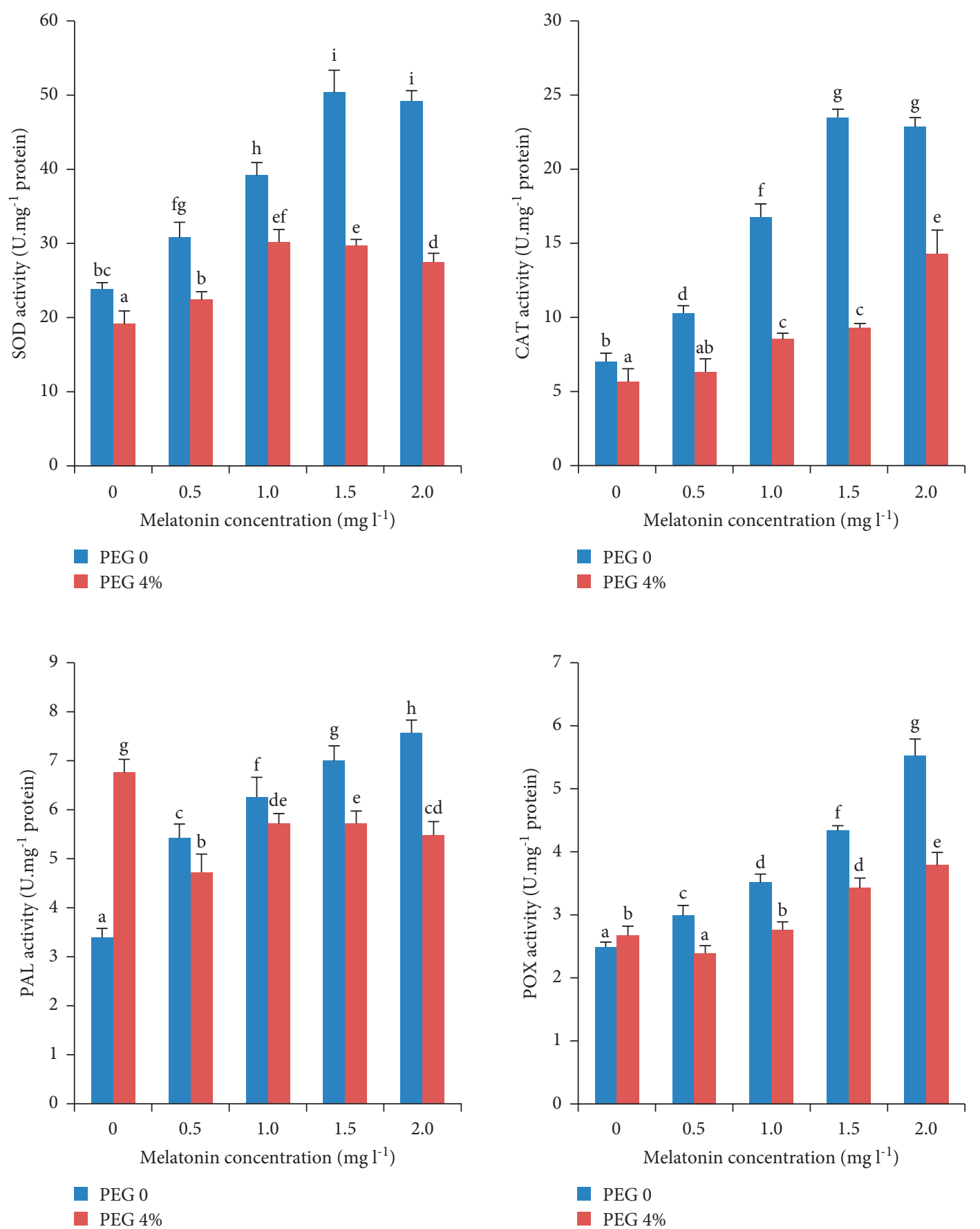

FIGURe 3: SOD, CAT, PAL and POX activity in H. pusillus calli cultures treated with melatonin concentrations and PEG levels after 28 days. Vertical bars indicate the standard errors of triplicates. Different alphabets indicate significant statistical differences between the mean values based on Duncan's test at $P \leq \% 5$. 

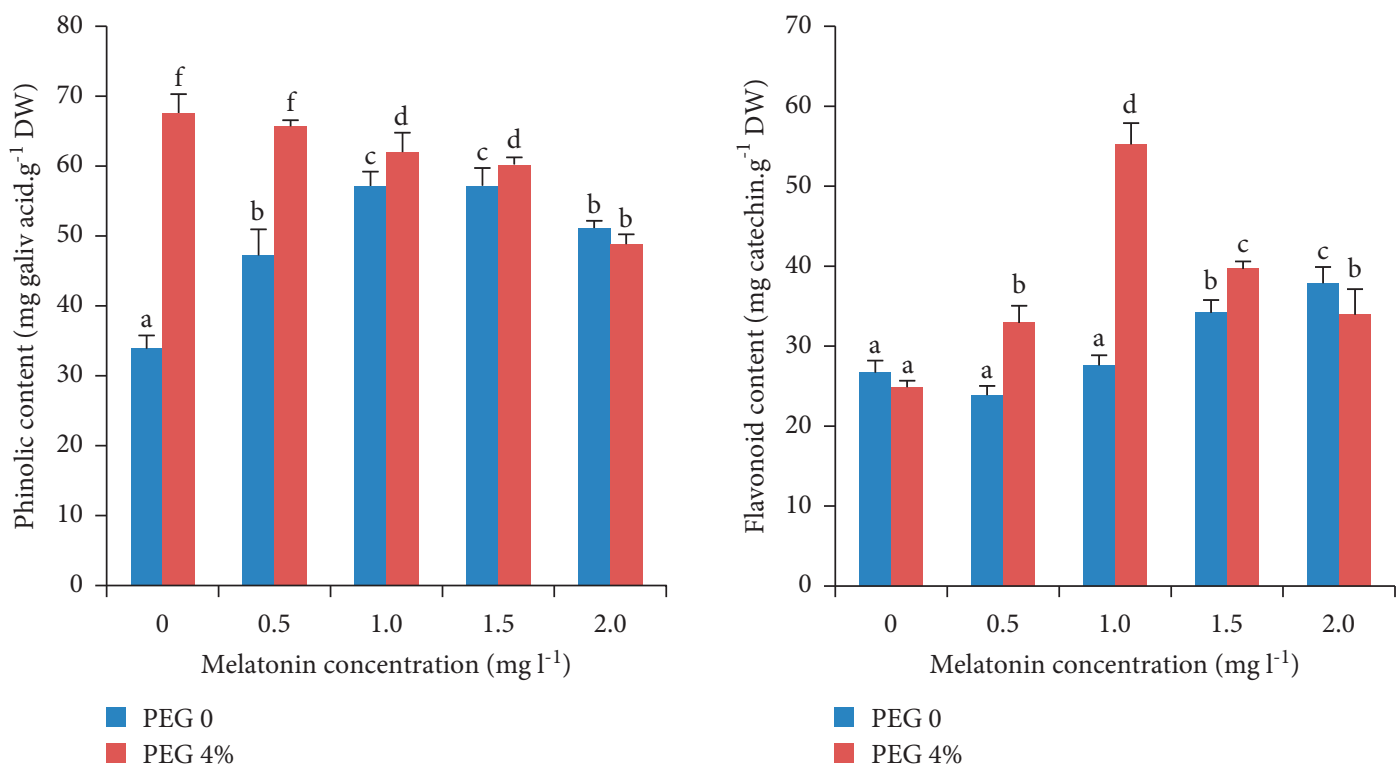

FIGURE 4: PC and FC activity in H. pusillus calli cultures treated with melatonin concentrations and PEG levels after 28 days. Vertical bars indicate the standard errors of triplicates. Different alphabets indicate significant statistical differences between the mean values based on Duncan's test at $P \leq \% 5$.

The $\mathrm{H}_{2} \mathrm{O}_{2}$ and MDA content treated with melatonin showed better protection of cellular membranes from oxidative stress. This is a guide for Melatonin role. In resistance of cellular membranes to oxidative stress damage, which was supported by Sharma and Zheng [58].

3.4. Antioxidant Activity Enzymes. SOD and ACT activity significantly increased in melatonin-treated $H$. pusillus calli cultures in media (with or without PEG) as shown in Figure 3.

Melatonin concentrations showed a significantly higher SOD activity in PEG-free media than their PEG-containing counterparts. The current study results revealed that the concentration of melatonin $1.5 \mathrm{mg} \mathrm{l}^{-1}$ achieved $50.63 \mathrm{U} \mathrm{mg}^{-1}$ protein and was 2.11 -fold higher than the comparison treatment. At the same time, melatonin improved this trait in PEG-treated callus cultures, especially with high concentrations of it.

As for CAT activity, the increased concentrations of melatonin played a prominent role in enhancing this trait. For example, the media of free drought condition with a concentration of $1.5 \mathrm{mg} \mathrm{l}^{-1}$ showed a mean value of CAT activity of $23.49 \mathrm{U} \mathrm{mg}^{-1}$ protein, 4-fold more, than that of the control treatment. However, the concentration of $2 \mathrm{mg}$ $1^{-1}$ was optimal in improving this trait under the drought condition, increasing 4- fold compared to the control.

PAL and POX activity significantly increased with melatonin concentrations when treated in $H$. pusillus calli cultures with or without PEG level as shown in Figure 3.

In the activity of PAL, there was a significant effect of PEG levels and melatonin concentration. The increased melatonin concentrations in the media of drought condition showed a similar increase in PAL activity. The highest mean values of $7.57 \mathrm{U} \cdot \mathrm{mg}^{-1}$ protein were obtained at a concentration of $2 \mathrm{mg} \mathrm{l}^{-1}$. Conversely, media containing PEG showed a significant decrease in this trait, increasing melatonin concentrations. The highest mean values was $6.76 \mathrm{U} \cdot \mathrm{mg}^{-1}$ protein in the control.

The activity of POX was significantly increased in callus cultures grown in media free from drought stress and treated with a high concentration of melatonin by 2.22 -fold, compared to the control. The combination of melatonin with PEG caused an enhancement of POX for callus cultures. A melatonin concentration of $2.0 \mathrm{mg} \mathrm{l}^{-1}$ increased this trait by $3.79 \mathrm{U} \cdot \mathrm{mg}^{-1}$ protein compared to the comparison treatment, which showed the lowest mean value $2.67 \mathrm{U} . \mathrm{mg}^{-1}$ protein

It was observed that melatonin effectively contributed to reducing stress induced by PEG by increasing the activity of the antioxidant enzyme system such as SOD, CAT, PAL, and POX that scavenge ROS [59]. Exogenous melatonin improves cellular growth. Furthermore, it stimulates genes expression and encoding antioxidant enzymes, which leads to resistance to abiotic stress [23].

3.5. Phenolic and Flavonoid Content. Phenolic compounds (PC) and total flavonoid (TP) significantly increased in melatonin treated $H$. pusillus calli cultures in media (with or without PEG) as shown in Figure 4. Melatonin concentrations showed a significant improvement in PC production in PEG-containing media compared to their non-containing counterparts. The current study results revealed that the control of melatonin achieved 67.6 and was 2.00 -fold more 
than the comparison treatment of PEG. At the same time, melatonin improved this trait in non-treated PEG callus cultures, especially with $0.5,1.0$, and $1.5 \mathrm{mg} \mathrm{l}^{-1}$ concentrations of it.

As for TF content, the increased concentrations of melatonin played a prominent role in enhancing this compounds.

For example, the media of drought condition with a concentration of $1.0 \mathrm{mg} \mathrm{l}^{-1}$ from melatonin showed a mean value of TF production of 55.23, 2-fold more, than that of the same concentration nontreated PEG. However, the concentration of $0.5 \mathrm{mg} \mathrm{l}^{-1}$ from melatonin was the lowest production of TF in cultures free of drought conditions.

PC and TP are nonenzymatic antioxidants. They are a class of secondary receptors known for their important biological effects. The enzyme PAL plays a major role in the synthesis of phenols. Therefore, we explain the increase in its production by the impact of the study treatments in increasing the activity of PAL enzyme [13].

\section{Conclusions}

In this study, the role of different melatonin concentrations in influencing $H$. pusillus calli cultures with or without drought stress by PEG is reported for the first time. The drought stress by PEG negatively affected all measured morphological, biomass, physiological, and biochemical traits. Melatonin enhanced PAL, POX, SOD, and CAT activity, which was positively reflected in the regulation of ROS level and the improvement of calli tolerance to PEG. Thus, morphological, FW, and DW traits are improved through melatonin in maintaining MSI, RWC, and Chl.T. These results will be helpful to compensate for the decline of the plant in the wild through the production of secondary compounds in vitro. Moreover, the present study provided knowledge that can be applied to drought tolerance by this plant. Thus, the reduction of wild-type constant attrition using plant tissue culture approaches. However, this study needs to define the role of the nonenzymatic oxidative system and understand the biological mechanisms that can cause diuresis in the production of secondary metabolites.

\section{Data Availability}

The data used to support the findings of this study will be available on request.

\section{Conflicts of Interest}

The authors declare that they have no conflicts of interest.

\section{Acknowledgments}

The authors are grateful to the University of Anbar, Center for Desert Studies, for providing the research supplies. The authors would also like to thank the technical assistants who assisted them in performing laboratory analyses and data collection.

\section{References}

[1] P. Silpa, K. Roopa, and T. Dennis Thomas, "Production of plant secondary metabolites: current status and future prospects," Biotechnological Approaches for Medicinal and Aromatic Plants, Springer, Singapore, pp. 3-25, 2018.

[2] Z. Yousaf, S. Masood, Z. K. Shinwari, M. I. R. Ajab Khan, and A. Rabani, "Evaluation of taxonomic status of medicinal species of the genus Hyoscyamus, Withania, Atropa and Datura based on polyacrylamide gel electrophoresis," Pakistan Journal of Botany, vol. 40, pp. 2289-2297, 2008.

[3] F. Nejadhabibvash, F. Rahmani, R. Heidari, R. Jamei, and F. Azimi, "Study of inheritance and environment on tropane alkaloids within Hyoscyamus species," Australian Journal of Crop Science, vol. 6, pp. 1428-1434, 2012.

[4] E. R. Elsharkawy, A. Ed-dra, E. M. Abdallah, and A. Shafa, "Antioxidant, antimicrobial and antifeedant activity of phenolic compounds accumulated in Hyoscyamus muticus L." African Journal of Biotechnology, vol. 17, pp. 311-321, 2018.

[5] H. Hank, E. Szoke, K. Toth, I. Laszlo, and L. Kursinszki, "Investigation of tropane alkaloids in genetically transformed Atropa belladonna L. cultures," Chromatographia, vol. 60, pp. 555-559, 2004.

[6] D. Hidalgo, R. Sanchez, L. Lalaleo, M. Bonfill, P. Corchete, and J. Palazon, "Biotechnological production of pharmaceuticals and biopharmaceuticals in plant cell and organ cultures," Current Medicinal Chemistry, vol. 25, pp. 3577-3596, 2018.

[7] E. Nielsen, M. E. F. Temporiti, and R. Cella, "Improvement of phytochemical production by plant cells and organ culture and by genetic engineering," Plant Cell Reports, vol. 38, pp. 1199-1215, 2019.

[8] T. Efferth, "Biotechnology applications of plant callus cultures," Engineering, vol. 5, pp. 50-59, 2019.

[9] A. Ranjbarfordoei, R. Samson, P. Van Damme, and R. Lemeur, "Effects of drought stress induced by Polyethylene glycol on pigment content and photosynthetic gas exchange of pistacia khinjuk and P. mutica," Photosynthetica, vol. 38, pp. 443-447, 2000.

[10] I. Turkan, M. Bor, F. Ozdemir, and H. Koca, "Differential responses of lipid peroxidation and antioxidants in the leaves of drought-tolerant P. acutifolius and drought-sensitive $P$. vulgaris subjected toand drought-sensitive $P$. vulgaris subjected to polyethylene glycol mediated water stress," Plant Science, vol. 168, pp. 223-231, 2005.

[11] A. Muscolo, M. Sidari, U. Anastasi, C. Santonoceto, and A. Maggio, "Effect of PEG-induced drought stress on seed germination of four lentil genotypes," Journal of Plant Interactions, vol. 9, pp. 354-363, 2014.

[12] S. I. Neamah, "In vitro production of some terpenoids compounds from Nigella sativa with different explants type and PEG concentration," Iraqi Journal of Agricultural Sciences, vol. 49, pp. 435-450, 2018.

[13] M. Sarmadi, N. Karimi, J. Palazon, A. Ghassempour, and M. H. Mirjalili, "Improved effects of polyethylene glycol on the growth, antioxidative enzymes activity and taxanes production in a Taxus baccata L. callus culture," Plant Cell, Tissue and Organ Culture, vol. 137, pp. 319-328, 2019.

[14] N. S. Hosseini, Z. G. Hagh, and H. Khoshgalb, "Morphological, antioxidant enzyme activity and secondary metabolites accumulation in response of polyethylene glycol-induced osmotic stress in embryo-derived plantlets and callus cultures of Salvia leriifolia," Plant Cell, Tissue and Organ Culture, vol. 140, pp. 143-155, 2020. 
[15] M. A. Ahmad, R. Javed, M. Adeel, M. Rizwan, and Y. Yang, "PEG 6000-stimulated drought stress improves the attributes of in vitro growth, steviol glycosides production, and antioxidant activities in Stevia rebaudiana Bertoni," Plants, vol. 9, p. 1552, 2020.

[16] M. B. Arnao and J. Hernandez-Ruiz, "Melatonin: possible role as light-protector in plants," in UV Radiation: Properties, Effects, and Applications, J. A. Radosevich, Ed., pp. 79-92, Nova Science Publishers, Hauppauge, NY, USA, 2014.

[17] R. Sharif, C. Xie, H. Zhang et al., "Melatonin and its effects on plant systems," Molecules, vol. 23, p. 2352, 2018.

[18] N. Zhang, Q. Sun, H. Li et al., "Melatonin improved anthocyanin accumulation by regulating gene expressions and resulted in high reactive oxygen species scavenging capacity in cabbage," Frontiers in Plant Science, vol. 7, p. 197, 2016.

[19] R. J. Reiter, L. Tang, J. J. Garcia, and A. Munoz-Hoyos, "Pharmacological actions of melatonin in oxygen radical pathophysiology," Life Sciences, vol. 60, pp. 2255-2271, 1997.

[20] Y. Zhao, L. Qi, W. Wang, P. K. Saxena, and C. Liu, "Melatonin improves the survival of cryopreserved callus of Rhodiola crenulata," Journal of Pineal Research, vol. 50, pp. 83-88, 2011.

[21] H. Kaur, S. Mukherjee, F. Baluska, and S. C. Bhatla, "Regulatory roles of serotonin and melatonin in abiotic stress tolerance in plants," Plant Signaling \& Behavior, vol. 10, Article ID e1049788, 2015.

[22] Y. Wang, R. J. Reiter, and Z. Chan, "Phytomelatonin: a universal abiotic stress regulator," Journal of Experimental Botany, vol. 69, pp. 963-974, 2018.

[23] H. J. Zhang, N. Zhang, R. C. Yang et al., "Melatonin promotes seed germination under high salinity by regulating antioxidant systems, ABA and GA4 interaction in cucumber (Cucumis sativus L.)," Journal of Pineal Research, vol. 57, pp. 269-279, 2014.

[24] C. Li, P. Wang, Z. Wei et al., "The mitigation effects of exogenous melatonin on salinity-induced stress in Malus hupehensis," Journal of Pineal Research, vol. 53, pp. 298-306, 2012.

[25] M. Sadak, "Mitigation of salinity adverse effects on wheat by grain priming with melatonin," International Journal of ChemTech Research, vol. 9, no. 2, pp. 85-97, 2016.

[26] M. A. Nawaz, Y. Jiao, C. Chen et al., "Melatonin pretreatment improves vanadium stress tolerance of watermelon seedlings by reducing vanadium concentration in the leaves and regulating melatonin biosynthesis and antioxidant-related gene expression," Journal of Plant Physiology, vol. 220, pp. 115-127, 2018.

[27] H. Fazal, B. H. Abbasi, N. Ahmad, and M. Ali, "Exogenous melatonin trigger biomass accumulation and production of stress enzymes during callogenesis in medicinally important Prunella vulgaris L." Physiology and Molecular Biology of Plants, vol. 24, pp. 1307-1315, 2018.

[28] M. Sadak and A. A. Ramadan, "Impact of melatonin and tryptophan on water stress tolerance in white lupine (Lupinus termis L.)," Physiology and Molecular Biology of Plants, vol. 27, no. 3, pp. 469-481, 2021.

[29] Y. Coskun, R. E. Duran, and S. Kilic, "Striking effects of melatonin on secondary metabolites produced by callus culture of rosemary (Rosmarinus officinalis L.)," Plant Cell, Tissue and Organ Culture, vol. 138, pp. 89-95, 2019.

[30] A. Catala, "The ability of melatonin to counteract lipid peroxidation in biological membranes," Current Molecular Medicine, vol. 7, pp. 638-649, 2007.

[31] V. Martinez, M. Nieves-Cordones, M. Lopez-Delacalle et al., "Tolerance to stress combination in tomato plants: new insights in the protective role of melatonin," Molecules, vol. 23, p. E535, 2018.

[32] S. J. Murch and P. K. Saxena, "Melatonin: a potential regulator of plant growth and development?" In Vitro Cellular and Developmental Biology-Plant, vol. 38, pp. 531-536, 2002.

[33] S. J. Murch, S. S. Campbell, and P. K. Saxena, "The role of serotonin and melatonin in plant morphogenesis: regulation of auxin induced root organogenesis in in vitro-cultured explant of St. John_s wort Hypericum perforatum L," In Vitro Cellular and Developmental Biology-Plant, vol. 37, pp. 786793, 2001.

[34] H. K. Lichtenthaler and C. Buschmann, "Chlorophylls and carotenoids: measurement and characterization by UV-VIS spectroscopy," Current Protocols in Food Analytical Chemistry, vol. F4, pp. 3.1-3.8, 2001.

[35] R. Sairam, "Effects of homobrassinolide application on plant metabolism and grain yield under irrigated and moisturestress conditions of two wheat varieties," Plant Growth Regulation, vol. 14, pp. 173-181, 1994.

[36] S. Karimi, A. Yadollahi, R. Nazari-Moghadam, A. Imani, and K. Arzani, "In vitro screening of almond (Prunus dulcis mill.) genotypes for drought tolerance," Journal of Biological and Environmental Sciences, vol. 6, pp. 263-270, 2012.

[37] V. Velikova, I. Yordanov, and A. Edrava, "Oxidative stress and some antioxidant systems in acid raintreated bean plants. Protective role of exogenous polyamines," Plant Science, vol. 151, pp. 59-66, 2000.

[38] C. H. R. De Vos, H. Schat, R. Vooijs, and W. H. O. Ernst, "Copper-induced damage to the permeability barrier in root of Silene cuiubalus," Journal of Plant Physiology, vol. 135, pp. 164-179, 1989.

[39] M. Gapinska, M. Skłodowska, and B. Gabara, "Effect of shortand long-term salinity on the activities of antioxidative enzymes and lipid peroxidation in tomato roots," Acta Physiologiae Plantarum, vol. 30, pp. 11-18, 2008.

[40] C. Beauchamp and I. Fridovich, "Superoxide dismutase: improved assays and an assay applicable to acrylamide gels," Analytical Biochemistry, vol. 44, pp. 276-287, 1971.

[41] M. P. Lesser, "Oxidative stress in marine environments: biochemistry and physiological ecology," Annual Review of Physiology, vol. 68, pp. 253-278, 2006.

[42] L. Lin and J. Wu, "Enhancement of shikonin production in single- and two-phase suspension cultures of Lithospermum erythrorhizon cells using low-energy ultrasound," Biotechnology and Bioengineering, vol. 5, pp. 78-81, 2002.

[43] F. B. Abeles and C. L. Biles, "Characterization of peroxidases in lignifying peach fruit endocarp," Plant Physiology, vol. 95, pp. 269-273, 1991.

[44] M. Thiruvengadam, N. Praveen, K. M. Maria John, Y. S. Yang, S. H. Kim, and I. M. Chung, "Establishment of Momordica charantia hairy root cultures for the production of phenolic compounds and determination of their biological activities," Plant Cell, Tissue and Organ Culture, vol. 118, pp. 545-557, 2014.

[45] S. Sanjaria, B. Keramata, and N. Nadernejada, "Ameliorative effects of 24-epibrassinolide and thiamine on excess cadmium-induced oxidative stress in Canola (Brassica napus L.) plants," Journal of Plant Interactions, vol. 14, pp. 359-368, 2019.

[46] S. Titov, S. K. Bhowmik, A. Mandal, and S. N. Uddin, "Control of phenolic compound secretion and effect of growth regulators for organ formation from Musa spp. cv. Kanthali floral bud explants," American Journal of Biochemistry and Biotechnology, vol. 2, pp. 97-104, 2006. 
[47] M. B. Arnao and J. Hernandez-Ruiz, "Melatonin and its relationship to plant hormones," Annals of Botany, vol. 121, pp. 195-207, 2017.

[48] S. A. Anjum, X. Xie, L. Wang, M. F. Saleem, C. Man, and W. Lei, "Morphological, physiological and biochemical responses of plants to drought stress," African Journal of Agricultural Research, vol. 6, pp. 2026-2032, 2011.

[49] S. Hajihashemi and A. A. Ehsanpour, "Influence of exogenously applied paclobutrazol on some physiological traits and growth of Stevia rebaudiana under in vitro drought stress," Biologia, vol. 68/3, pp. 414-420, 2013.

[50] T. Khan, M. A. Ullah, L. Garros, C. Hano, and B. H. Abbasi, "Synergistic e_ects of melatonin and distinct spectral lights for enhanced production of anti-cancerous compounds in callus cultures of Fagonia indica," Journal of Photochemistry and Photobiology B, vol. 190, pp. 163-171, 2019.

[51] M. Nazir, M. A. Ullah, S. Mumtaz et al., "Interactive effect of melatonin and UV-C on phenylpropanoid metabolite production and antioxidant potential in callus cultures of purple basil (Ocimum basilicum L. Var purpurascens)," Molecules, vol. 25, p. 1072, 2020.

[52] C. Y. Chen, G. Wu, and M. Z. Zhang, "The effects and mechanism of action of Prunella vulgaris L. extract on Jurkat human Tlymphoma cell proliferation. Chinese-German," Journal of Clinical Oncology, vol. 8, pp. 426-429, 2009.

[53] M. Ashoori, S. Ashraf, and Z. T. Alipour, "Investigating the effect of two species of mycorrhiza fungi and salinity on growth, function and chlorophyll content on Ocimum basilicum," International Journal of Agriculture and Crop Sciences, vol. 8, p. 503, 2015.

[54] A. A. Mozafari, S. Dedejani, and N. Ghaderi, "Positive responses of strawberry (Fragaria $\times$ ananassa Duch.) explants to salicylic and iron nanoparticle application under salinity conditions," Plant Cell, Tissue and Organ Culture, vol. 134, pp. 267-275, 2018.

[55] S. I. Neamah and A. H. Hamad, "The effects of paclobutrazol on enhancing tolerance of Plantago major L. to cadmium stress in vitro," Australian Journal of Crop Science, vol. 14, no. 12, pp. 2028-2035, 2020.

[56] M. F. M. Ibrahim, O. H. Abd Elbar, R. Farag et al., "Melatonin counteracts drought induced oxidative damage and stimulates growth, productivity and fruit quality properties of tomato plants," Plants, vol. 9, p. 1276, 2020.

[57] X. Ma, J. Zhang, P. Burgess, S. Rossi, and B. Huang, "Interactive effects of melatonin and cytokinin on alleviating drought-induced leaf senescence in creeping bentgrass (Agrostis stolonifera)," Environmental and Experimental Botany, vol. 145, pp. 1-11, 2018.

[58] A. Sharma and B. Zheng, "Melatonin mediated regulation of drought stress: physiological and molecular aspects," Plants, vol. 8, p. 190, 2019.

[59] M. A. El-Esawi, A. Elkelish, M. Soliman, O. Elansary, A. Zaid, and S. H. Wani, "Serratia marcescens BM1 enhances cadmium stress tolerance and phytoremediation potential of soybean through modulation of osmolytes, leaf gas exchange, antioxidant machinery, and stress-responsive genes expression," Antioxidants, vol. 9, p. 43, 2020. 